\title{
The Name Jar Project: Supporting Preservice Teachers in Working with English Language Learners
}

\author{
THEODORA KAPOYANNIS \\ University of Calgary
}

\section{Abstract}

Classrooms are becoming more linguistically and culturally diverse and many educators are feeling unprepared to meet the varied needs of English language learners (ELLs). Through a larger design-based research doctoral study, I collaborated with 11 preservice teachers and 28 ELLs in Grades 2 and 3 to design and implement a literacy intervention that focused on cultivating literacy engagement to foster English language development. This paper documents the positive impact the implementation of the literacy intervention, also known as the Name Jar Project, had on supporting the preservice teachers' emerging practice. Analysis of focus group data, preservice teachers' written reflections, and field notes revealed that (a) the preservice teachers, through their informal learning experiences, were able to empathize with the ELLs' strengths and challenges of learning English; (b) the service learning model provided a safe learning environment for preservice teachers to gain practical experience working with ELLs; and (c) through the research design, preservice teachers connected practice and theory to inform their future teaching experiences.

Keywords

English language learners, ELLs, preservice education, literacy, language learning

\section{Background}

Kindergarten to Grade 12 (K-12) classrooms are becoming more linguistically and culturally diverse with an increasing number of students who speak a language other than English at home (Samson \& Collins, 2012; Statistics Canada, 2017). I use the term English language learners (ELLs) to refer to learners who do not speak English as their mother tongue. It has been well recognized that many ELLs face challenges in achieving high literacy levels (August \& Hakuta, 1998; Collier, 1995a, 1995b; Roessingh, 2018; Roessingh \& Kover, 2003). Academic language becomes gradually more difficult for ELLs as they try to keep up with the conceptual and linguistic demands of the curriculum (LinanThompson \& Vaughn, 2007; Roessingh, 2018). In this regard, as ELLs move on to higher grades, they are required to read and understand increasingly difficult texts in the curricular content areas. This complexity reflects academic language with a high vocabulary load, including many low-frequency and technical words that are seldom used in typical conversation (Cummins, 2011a; Roessingh, 2018).

For educators, this also presents many difficulties as they try to support both the language and literacy needs of a diverse student population. Many inservice and preservice teachers also feel challenged in being responsive to the linguistic and cultural diversity in their classrooms (Alberta Teachers' Association, 2014; Kapoyannis, 2019; Goldenberg, 
2013; Howard Research \& Management Consulting, 2006, 2009; International Literacy Association, 2017; Roessingh, 2011; Samson \& Collins, 2012). To address the literacy and language needs of young ELLs, it is essential for educators to continue to reflect on the role of first language and culture in classrooms (Kapoyannis, 2019; Cummins, 2011a, 2011b; Cummins \& Early, 2011; Goldenberg, 2013; Naqvi et al., 2012; Roessingh, 2011; Toohey \& Dagenais, 2010).

Using design-based research (DBR) principles, I collaborated with 11 preservice teachers to design and implement a literacy intervention called the Name Jar Project to support the literacy and language needs of 28 ELLs in grades 2 and 3. This literacy intervention was part of a larger doctoral study that took place in a diverse urban school board in Calgary, Alberta that inquired into the primary research question: How can educators cultivate literacy engagement to support English language development? The study took a two-pronged approach where I examined the impact the literacy intervention had on meeting the literacy and language needs of the young ELLs and how the implementation of the intervention supported the preservice teachers' emerging practice. This paper focuses on the latter prong, the positive impact the DBR study had on supporting the preservice teachers' practice, and explores the following questions:

- What experiences and/or background did the preservice teachers have in supporting the ELLs coming into the study?

- How did the implementation of the designed literacy intervention support the preservice teachers' emerging practice in being responsive to the linguistic and cultural needs of ELLs?

\section{Literature Review}

\section{Supporting ELLs in Alberta}

A review initiated by Alberta Education on Kindergarten - Grade 12 (K-12) English as a Second Language (ESL) education provided key findings and recommendations (Howard Research, 2006, 2009). The purpose was to identify the optimal supports and strategies needed to support the educational achievement of ELLs and to assist Alberta Education with decisions related to curriculum development, resource allocation, and support provision (Howard Research, 2006). The report summarized that in order to personalize instruction for ELLs, there is a need for all educators, not just ESL teachers and ESL assistants, to have a greater understanding about the pedagogical knowledge related to working with ELLs in the mainstream classroom. This pedagogical knowledge includes a more informed understanding about the process of second language acquisition and acculturation, instructional design that supports linguistic and conceptual understanding, and ways to work more closely with parents and communities to understand the linguistic and cultural profiles of ELL learners (Goldenberg, 2013; Roessingh, 2014). Preservice teacher education was also specifically addressed noting that data collected from case studies and expert-stakeholder meetings indicated that preservice teachers are limited in the number and breadth of ESL-related courses that can be included in their undergraduate programs. The review's recommendation strongly promoted creating more opportunities for inclusion of ESL related courses in teacher education programs and more placement opportunities for student teachers in schools with large numbers of ELLs 
(Howard Research, 2006). The reports also underscored the importance of professional development and professional development opportunities for inservice and preservice teachers and that being responsive to the needs of ELLs was more than good teaching practices. There was a priority on working more closely with pre-service teachers around the pedagogical knowledge needed to work more effectively with ELLs and on the importance of school leaders in supporting their school staffs around this professional learning process.

This is echoed in the current literature, indicating that educators need to continue to reflect on the implications of linguistic diversity for educational practice (Cummins, 2011a, 2011b; International Literacy Association, 2017; Ntelioglou et al.,2014) This sentiment is supported in a recent synthesis of literature on responsive instruction for ELLs. Goldenberg (2013) asserted, "Although generic effective instruction is almost certainly a necessary base, it is probably not sufficient to promote accelerated learning among English Learners" (p. 6). He further highlighted the importance of focusing on intentional English language development for ELLs and promoted promising instructional practices such as using the home language to support academic development.

\section{Theoretical Lenses}

\section{Multiliteracies Approach.}

Alberta Education's (2010) definition of literacy is rooted in a multiliteracies approach where multiple modes of meaning making, and communication are emphasized. Literacy teaching is seen beyond skills and competence where meaning making is active, dynamic, and process oriented. Multiliteracies approach, first proposed by the New London Group (1996) disrupts traditional notions of reading and writing to include broader notions of literacy, including linguistic, visual, audio, spatial, and performative modalities. These broader notions of literacy are premised on the changing dimensions of language use today, which emphasize the need for learners to figure out differences in patterns of meaning from one context to another. It also embraces that meaning is made in multimodal ways to respond to new information and communication media of 21st century learning environments (Cope \& Kalantzis, 2009).

To build a sense of belonging and equitable opportunities in classrooms today, not only must the role of first language and culture be recognized within a multiliteracies approach, but also opportunities for students to represent their learning through a multilingual and multimodal lens must be provided.

\section{Literacy Engagement Framework}

The design of the literacy intervention draws on the instructional dimensions of the literacy engagement framework (Cummins \& Early, 2011) which explores literacy engagement through the lens of working with linguistically and culturally diverse students. Cummins (2011a) discussed the critical relationship between literacy engagement and literacy achievement and argued that this relationship has not been explicitly articulated in school policies for ELLs. Access to print materials and extensive reading play a causal role in students' literacy achievement through opportunities to cultivate strong reading comprehension skills and broaden vocabulary knowledge (Lindsay, 2010). Literacy 
engagement will be enhanced when (a) students' prior knowledge is activated, (b) their ability to understand and use academic language is supported through specific instructional strategies, (c) their identities are affirmed, and (d) their knowledge of and control over language is extended across the curriculum (Cummins\& Early, 2011).

There is consensus in the current literacy research about the relevance of scaffolding instruction, activating background knowledge, and extending language of literacy engagement (Cummins \& Early, 2011), but there is minimal acknowledgement of how educators affirm students' identities. In recent years, many researchers have expressed the need for first language and culture to be acknowledged in the development of the English language if educators are to affirm a student's identity and embrace plurilingualism (the continued development of home languages) in classrooms (Kapoyannis, 2019; Cummins, 2011a, 2011b; Cummins \& Early, 2011; Naqvi et al., 2012; Roessingh, 2011; Toohey \& Dagenais, 2010).

\section{Informal Learning Experiences}

The research study provided preservice teachers an informal learning experience through the service- learning project. Formal learning is typically institutionalized, sponsored, classroom-based, and highly structured. Most adult learning occurs outside of formal education and is referred to as informal or experiential learning (Dominice, 2000). Informal learning is not typically classroom based or highly structured, and control of learning rests primarily in the hands of the learner. Through authentic learning experiences, adult learners reflect on what is known and how meaning is extracted from experience.

Professional learning applying current research findings on languages and diversity is imperative if educators are to meet ELLs' personalized needs and ensure academic achievement (Kapoyannis, 2019; Cummins \& Early, 2011; Escamilla, 2009; Goldenberg, 2013; Naqvi et al., 2012; Roessingh, 2011). To assist the participating preservice teachers in implementing the Name Jar Project, I designed three structured workshops (approximately $2 \mathrm{hr}$ per session) at the local university the preservice teachers attended. I was able to gather information on the personal and professional experiences that they were bringing to the study as well as what they were hoping to gain from their participation. I summarized the literature review and theoretical framework informing the study and gave an overview of the research problem and questions. I encouraged the pre-service teachers to ask questions and to contribute their insights into the research problem. The sessions also included lesson and material development in preparation for the contact hours with the students at the research site. These coaching and professional learning opportunities provided the first-year pre-service teachers with the time to expand on their understanding of second language pedagogy, to collaborate with peers to design learning tasks based on the objectives of the intervention, and to prepare themselves for the $20 \mathrm{hr}$ of contact time with the ELLs at the research site.

To provide an exemplar of how the preservice teachers explored the theoretical underpinnings informing the study, I invited them to consider the use of artifacts as a way to engage the students they would be working with. I asked the pre-service teachers to come prepared to discuss the storybook The Name Jar, which would be used during the literacy intervention and to bring an artifact that was meaningful to them in connection with their names. We discussed how they could model this for the young ELLs during the 
intervention. I began this professional learning opportunity by sharing my own artifact to model the process and begin the conversation. The preservice teachers shared their artifacts in small groups as they learned more about one another, their languages, and their cultures. The artifacts included sentimental gifts from home countries, photos and jewelry. Together, the pre-service teachers and I debriefed as a large group, reflecting on the use of artifacts as a way to engage ELL students through this multiliteracies approach and how they could be used in creating an identity text. I was able to write field notes during these initial professional learning sessions to deepen my understanding of the preservice teachers as participants, their experiences coming into the study, and their perspectives about supporting literacy and language needs of young ELLs.

Throughout the research project, we created a community of practice $(\mathrm{CoP})$ to meet the preservice teachers professional learning needs. A CoP is defined as "groups of people who share a concern, a set of problems, or a passion about a topic, and who deepen their knowledge and expertise in this area by interacting on an ongoing basis" (Wenger et al., 2002 , p. 4). In our CoP, we held weekly meetings to discuss the literacy sessions and create an emergent support system. The meetings provided informal opportunities to bridge theory and practice by discussing how the literacy sessions were going, looking at student work, and sharing instructional strategies with one another. This job-embedded professional learning also provided the preservice teachers an opportunity to reflect on their lessons with their peers, share ideas, and, with guidance, make adjustments to the design of the lessons. The COP also had an online component through the Desire to Learn (D2L) shell that I created to support the teachers with sample lessons, instructional strategies, models, and readings.

\section{Methodology}

\section{Setting and Participants}

The 11 preservice teachers, two men and nine women, were recruited from the firstyear cohort of a two-year Bachelor of Education (BEd) After Education degree at a local university who had volunteered to participate in a service- learning project to support ELLs. This service- learning project was one of many opportunities offered to undergraduate students to gain more experience in working in diverse settings. All 11 participants had completed first degrees in various disciplines and had a keen interest in learning more about how to meet the diverse needs of young ELLs in their practice. They were appreciative of the opportunity to be part of a cohort of 11, continuing in the same school to complete their four-week practicum requirements.

The preservice teachers committed to 20 contact hours with the grade 2 and 3 students and an additional five hours of professional learning time with me and with other staff members at the school site. Literacy sessions at the school site took place twice a week for $60 \mathrm{~min}$ per session.

Only one of the 11 preservice teachers had any formal coursework in supporting ELLs as he was specializing in teaching English as an additional language in his program.

The project took place in an elementary school (K-6) within a large urban board in Alberta that prioritized literacy as an overall school focus. The school demographics reflected the learning needs of a linguistically and culturally diverse school population and 
benefitted from the proposed intervention. The school's population during the project was 544 students with 114 of them coded as ELLs. Working with the school administration, 29 students in grades 2 and 3 were identified as meeting the criteria for the study: (a) identified as an ELL by Alberta Education in grades 2 and 3 and (b) had an intermediate (level 3) English language proficiency and higher according to the provincial ESL Benchmarks (Alberta Education, 2012). The participants were both foreign born (301) born outside of Canada and Canadian born learners (303) coded as ELLs. I chose this proficiency criterion purposefully to ensure that the emphasis was not on teaching beginning early literacy skills such as phonemic awareness but to rather on vocabulary tasks that would build background knowledge and comprehension to support academic literacy.

\section{Design Based Research (DBR)}

DBR emphasizes a pragmatic orientation involving a choice of mixed methods and a variety of research tools to respond to complex and authentic educational problems (Brown, 1992). This methodology takes an interventionist approach; it is collaborative, grounded in the literature, and shaped by field testing and participant expertise (McKenney \& Reeves, 2012). The research project took place over a 6-month period to allow for the four core phases of DBR research to take place. These four core phases of DBR are further elaborated on below:

Phase 1 of DBR begins with an investigation of the problem at hand, entailing an exploration and analysis of the existing situation in terms of current knowledge and practice. The educational problem that the research will address is identified and analyzed through a literature review and in consultation with practitioners.

Moving into Phase 2, the design/construction phase, the emphasis is on drafting and prototyping solutions for the research problem and questions being explored. The literature is consulted again to find relevant theory to guide the solution as well as existing design principles that may address the research problem and questions. This informs the design of the planned intervention with draft principles, which will be reflected in practice within the learning environment.

Phase 3 is the implementation and evaluation of the proposed solution in practice, which will inform the first implementation cycle of the intervention. In this phase, there are considerations as to how the design solutions will be implemented and evaluated. This includes who the participants will be, what procedures will be used to implement the solution, and what data will be collected and analyzed to inform the research questions.

Phase 4, the final phase of evaluation and reflection, incorporates the idea that results influence subsequent design cycles and the need for reflection as part of the process to produce design principles and impact implementation of solutions (McKenney \& Reeves, 2012). Data is gathered to determine the impact of the intervention and the reflections and insights inform future cycles of implementation.

\section{Designing the Literacy Intervention}

Using DBR principles (Amiel \& Reeves, 2008; Anderson \& Shattuck, 2012; Brown, 1992), I worked with the preservice teachers (also known as the ELLs' university buddies) to design and implement the literacy intervention. The designed literacy intervention, called the Name Jar Project, used the storybook The Name Jar (Choi, 2001) 
to anchor sequenced and linked literacy tasks that resulted in the creation of identity texts about how ELLs make meaning of their names.

The storybook was chosen as an exemplar of a culturally relevant text which provides students with the opportunity to engage with texts that connect to their cultural backgrounds (Freeman \& Freeman, 2004). These books can also include dual language books written in both English and L1 to reflect the language and cultures of the students. They focus on deeper concepts such as belonging, legacy, cultural artifacts, and relationships that form semantic networks for understanding and making sense of the world (Kramsch, 2004).

Using the Name Jar book provided an anchor to develop literacy tasks to support the ELLs in creating identity texts as part of the intervention. Identity texts are practical and pedagogically sound artifacts focused on embracing the student's first language and culture by creating a learning space where students' identities are reflected back in a positive manner (Cummins \& Early, 2011; Naqvi et al., 2012; Roessingh, 2011). These texts can take on multimodal forms: written, spoken, visual, dramatic, or a combination of arrangements (Cummins \& Early, 2011; Cummins et al., 2015; Stille \& Prasad, 2015). The literacy intervention was delivered by the preservice teachers through a progression of 10 lessons using the Learning by Design (Roessingh, 2010) curricular framework implemented over 20 literacy sessions in small group configurations. I used the Learning by Design website (Roessingh, 2010a) as a curricular framework to guide lesson planning for the literacy sessions focusing on how young ELLs made meaning of their names. This framework incorporated both linguistic and conceptual learning objectives through opportunities to integrate multimodal and multilingual literacy tasks.

Through consultation with the relevant literature and input from the preservice teachers, we created design principles to guide the literacy intervention focused on cultivating literacy engagement to support English language development (see Table 1). Using these design principles and strategies for implementation, the preservice teachers delivered the intervention through 10 guiding lessons that made up the curriculum for the literacy sessions and provided a prototype of the intervention. Through this adaptable implementation, we had opportunities to modify and redesign lessons to personalize the literacy sessions and for the preservice teachers to provide input into future iterations of the intervention. For a more detailed description of the curricular framework and how the intervention was implemented, please see (Kapoyannis, 2019).

Table 1

Design Principles Guiding Literacy Intervention

\begin{tabular}{ll}
\multicolumn{1}{c}{$\begin{array}{c}\text { Design principles guiding } \\
\text { intervention }\end{array}$} & \multicolumn{1}{c}{ Strategies to support implementation } \\
\hline $\begin{array}{l}\text { Provide intentional } \\
\text { scaffolding and modeling } \\
\text { opportunities for English } \\
\text { language development }\end{array}$ & $\begin{array}{l}\text { Use of learning by design curricular framework } \\
\text { (Roessingh, 2010) for lesson development, additional } \\
\text { scaffolding, and modeling resources for preservice } \\
\text { teachers to use on D2L shell. }\end{array}$ \\
\hline \hline Language and Literacy & Volume 23, Issue 3, 2021
\end{tabular}


Promote and value use of first language and culture

Provide opportunities for extension of academic language

Support practitioners through experiential and situated learning opportunities
Encouragement of first language and culture through dual language opportunities, shared reading of culturally relevant text, name artifacts, and creation of identity texts

Extension of academic language through a focus on developing and recycling tiered vocabulary, curricular connections, vocabulary development tasks with multiple exposures to new words.

Reflection on literacy sessions, D2L shell to provide resources and models to support preservice teachers.

Note. D2L (Desire2Learn) is an online learning platform.

\section{Data Sources}

In this section, I describe each of the data sources collected during the research project, including field notes, focus group data, and preservice teachers' reflections of the literacy sessions.

Field notes. I wrote field notes and memos as I observed the literacy sessions in the small group configurations, reflected on the professional learning sessions, and situated myself overall at the research site with the staff, ELLs, and preservice teachers. I kept these notes in my field journal and secured them within the ethical guidelines of this study.

Focus group data. I conducted two focus groups with preservice teachers to gather data about their experiences with literacy practices supporting ELLs. Both were audiorecorded and transcribed, using pseudonyms. Focus groups are a form of qualitative interviewing that provides the opportunity for participants who share a similar background to engage in meaningful conversations about the topics researchers wish to understand (Morgan, 2008). I moderated the focus groups and used semi structured questions (see Appendix A) to get the preservice teachers' perspectives and insight on literacy engagement and this intervention.

Literacy session reflections: Secondary data. As part of the lesson template (see Appendix B), the preservice teachers could record their observations and reflections. Each week, they typed their reflections on their literacy sessions and submitted them to me. These observations became secondary data and were concurrently collected and analyzed to help guide and redesign the literacy intervention as the study progressed.

\section{Data Analysis}

Using constant comparison analysis (Onwuegbuzie et al., 2009; Parry, 2004; Strauss \& Corbin, 1998), a three-stage analysis process of open, axial, and selective coding was used to analyze the data. Analysis begins with open coding where the data is chunked 
into smaller units attaching a code or descriptor to the unit. The codes are emergent, meaning that the descriptors emerge from the data. During the second stage, which is referred to axial coding, the codes are grouped into categories of information and positioned within a theoretical model. In the last stage, quotes are placed into the relevant categories and one or more themes are then developed that express the content of each of the categories referring to the final stage of selective coding (Strauss \& Corbin, 1998).

In analyzing the focus group data, I used memos (Morgan, 2008) to capture reflections that came to mind, with particular attention to topics that generated high levels of interest from most participants in each focus group as well as the consistent repetition from a single participant about a particular topic or theme. Morgan (2008) discussed how "capturing notes of what you see and hear creates a secondary back up record of the session and it can fill important blanks when you start analyzing the recorded materials (p. 36). As I conducted two rounds of focus groups with the pre-service teachers, it was important to look for themes, patterns, and relationships across the data. It was also essential to explore the outlying data that did not fit the patterns emerging. This is critical to the analysis by exploring exceptions and contradictions around a particular theme. This early data analysis shaped the gathering of additional data through following up with individual participants to ensure data checking and gain further insight to inform other questions to address in the second focus group.

Through this process, themes emerged to determine the positive impact the designed literacy intervention had on supporting the preservice teachers' emerging practice. Through constant comparison analysis, a point of saturation is reached where no new information and understanding are generated. Findings are grounded in the data set, and the themes that are identified can be illustrated though multiple data fragments (quotes) (Lincoln \& Guba, 1985). This first implementation cycle of the literacy intervention, implemented by 11 pre-service teachers over 20 literacy sessions, provided multiple sources of data to guide future iterations. This triangulation of data provided internal validity and also contributed to the reliability of the study referring to what extent the study can provide the same results when replicated.

\section{Findings}

Three major themes emerged in response to the research questions: (a) the preservice teachers were able to empathize with the strengths and challenges of learning English through their informal learning experiences, (b) implementing the intervention through the service learning model provided a safe learning environment for preservice teachers to gain practical experience working with ELLs, and (c) implementation of the intervention provided the preservice teachers with opportunities to connect practice and theory and to inform their future teaching experiences. I present the themes with relevant data as evidence.

Finding 1: The preservice teachers were able to empathize with the strengths and challenges of learning English through their informal learning experiences.

The 11 first-year preservice teachers identified few formal learning experiences in their education program to support linguistic and cultural diversity. They were not required to take any formal coursework in Teaching English as an Additional Language (TEAL). 
Of note, they had only completed one field experience, focused mostly on observation, before starting the Name Jar Project. The preservice teachers identified their personal experiences working with ELLs, the need for more support in their education program in learning how to differentiate for diversity, and their perceptions of the strengths and challenges in learning English for ELLs.

Making sense of experience: Informal and formal learning experiences. The preservice teachers explained in the focus group that they were exposed to some initial theoretical underpinnings and strategies in their pragmatics course to support the ELLs, but they identified the need to have more formal and informal learning opportunities in their education program to work with ELLs and be able to differentiate for linguistic and cultural diversity. Christina noted a lack of support on this topic: "[The pragmatics professor] taught us a lot in our pragmatics class, so I think I have had a great introduction, . . . but other than that, I don't have a lot." Yana said, "You don't get support around differentiating for diversity in this program unless you take inclusive or ELL specialization."

Jessica agreed:

Yeah, my interactions were mostly in school, in grade school. They (ELLs) were pulled out of class but I don't think until I was in this kind of role and in this school that you see how often they are pulled out and how much it can affect them. I think we take it for granted, our interaction with the language, and say, "Oh, it's simple." But even working with these kids, ... it's like they use the common use of the word "good" for so many things. Like, when I was in Grade 2, I was using harder words, using more advanced words, but you take it for granted. You don't think about it like that.

These quotes reinforce that the preservice teachers had few formal learning experiences working with ELLs coming into the project. Yana's quote captures the perception that differentiating for diversity is addressed only through the inclusive and ELL specializations and not part of other education courses. All preservice teachers consistently identified the need for more support in learning how to differentiate for linguistic and cultural diversity in their education courses.

Identifying the strengths and challenges in learning English for young ELLs. Through reflecting on their personal experiences, the preservice teachers identified strengths in learning English for ELLs as well as the challenges many ELLs and their families may face within their schooling experiences. Elliot shared an anecdote on the diverse learner profiles of ELLs:

I know some people; they are remarkable. She's a speech pathologist, and he is an elementary principal. He is from Slovakia, and she's from here, and the first two kids are adopted, and they are Blackfoot. So then they learned English and Slovakian, because the grandparents speak Slovakian, and then they go to French immersion school. So, they learn English at home, Slovakian on Saturdays. They already knew Blackfoot, and they are going to school for French. Then they have three biological kids, all under 10 years old, and they are all learning the three languages. 
The preservice teachers also perceived strengths in learning other languages. As Ariana noted,

I nannied . . . for the same family for seven years. . . So their mom is German, and their dad is Canadian, but their mom only spoke German to them. The youngest one was born in the United [Arab] Emirates and only spoke German with his mom. When he went to preschool, he didn't know that much English even though she [the mother] speaks fluent English. She spoke to them in German because she wanted them to learn German. And then much later, they moved to Switzerland. All of them had a hold of spoken German but couldn't read and write in it. Because he [the youngest] only spoke German going in, he picked up English much easier.

Both of these quotes speak to the diverse global profile that is part of 21 st century classrooms, where multiple languages and cultures are represented. The preservice teachers also recognized that linguistic and cultural experiences vary based on personal experiences, the motivation to learn different languages, and family dynamics, among other factors. They realized that English language development is not a static process. In these examples, the preservice teachers elaborated on their positive perceptions towards learning other languages and how first language learning supports the learning of additional languages.

The preservice teachers also described the challenges they perceived in learning other languages and the time it takes to develop competency in English. Kaitlyn provided a personal example related to her partner's English language proficiency and her perspective on learning English:

Actually, my partner is an ELL, and he has only been in Canada for five years. . . . [He] studied English in Mexico since he was eight years old. What I've really realized is that he still needs a lot of help with English even though he is working on a job in Canada and doing well for himself. Learning English or a second language is a lifelong endeavour, something you will always be working on, and it won't be the same as if it was your first language. I just thought it was interesting that he [still] needs a lot of help.

Kaitlyn's personal experience has allowed her to observe her partner's English language proficiency, recognize the complexity in learning a second language, and understand that learning a second language requires time, is a long process, and needs to be supported.

Finding 2: Implementing the intervention through the service learning model provided a safe learning environment for preservice teachers to gain practical experience working with ELLs.

The preservice teachers saw participation in this service- learning project as a positive, relevant, and practical opportunity to become more confident in meeting the needs of young ELLs in linguistically and culturally diverse classrooms. They appreciated the opportunity to stay in the same school as a cohort for both the service-learning project and their second one-month practicum. In this section, I elaborate on how the preservice teachers viewed service learning as a way to gain practical experience, the power structures that are perceived in field experiences, and how CoPs can support emerging professionals.

Service Learning as a way to gain practical experience. During the focus groups, the preservice teachers described the project as a way to gain practical experience with ELLs without the pressure they have sometimes felt with more formal field experiences. 
The preservice teachers started to take more risks in trying out different strategies and then adjusting their lessons based on their observations and reflections. Working with fewer students, they started to gain more confidence as the project progressed without feeling that they were being evaluated. Elliot commented, "It's nice to do it on your own without teachers watching you and you're more nervous. It's like, 'I'm going to try this today, and if it doesn't work, I'm going to change it next time." Y Yana seconded this observation:

I would like to add confidence to that. You're building personal relationships on a smaller level with individual students, and then you gain the confidence to use the strategies you are using in your practicum with your classroom. It just makes you gain confidence and comfort, as was mentioned.

Both of these quotes illuminate the importance of the service- learning project in bolstering the preservice teachers' confidence to reflect on their practice, adjust their lessons in a safe environment, and apply their learning to the larger classroom.

Preservice teachers' vulnerability and power structures within field experiences. Through the focus group data, preservice teachers' lesson reflections, and my field notes, the theme of power became apparent. The preservice teachers came into the project with some hesitation, unsure if they could implement the intervention. They brought up several times that not being evaluated gave them the space to gain more confidence in their own practice.

I started to think about my role as a researcher and how it was influencing the learning environment and my relationship with the preservice teachers. Being reflexive in the process is important in recognizing the biases and assumptions a researcher brings to a study. Simons (2009) stressed that it is important for researchers to situate themselves within the research process and to reflect on how their values and judgments affect their portrayal of them with the research participants. My background and experiences as an educator, student, and ELL myself, allowed me to make sense of many observations in the field, but I had to be cognizant of when my emotions were engaged and how it was influencing the process. In most of my experiences working with preservice teachers, I have had an evaluative role within formal learning experiences. I reflected on how the power dynamic started to shift for me, too, within the DBR process. By design, I was not there to evaluate the preservice teachers but to collaborate with them to glean insight into the research questions. This shift contributed to a safe learning environment where all project members gained confidence in what was being done and worked together to support the young ELLs. This informal service-learning opportunity thus orchestrated an environment where the preservice teachers felt safe to take more risks. There was enough structure in the models and resources available to them to scaffold the lessons, yet they also appreciated the encouragement to adjust lessons and use different strategies when they were ready to do so.

The following lesson reflections from two of the preservice teachers capture this idea. Blake said, "I know at the beginning it felt a bit overwhelming, but we have so many resources that are available with this project that we can use, which is very helpful." Christina commented,

I really appreciated overcoming my fear that I wouldn't be able to do this. We had a lot of fun doing it, and that gave me a lot of confidence moving forward. I learned 
about building a rich context around the language building and bringing something concrete, like artifacts. That was helpful for me to see this process. I think I talked about this in my last reflection. This aha moment I had that students were making connections between their first and second language and how cool it was that that was part of their identity.

These quotes capture the preservice teachers' initial hesitation and uncertainty about their own abilities in participating in this project, and their appreciation of the resources that were in place to support them with the literacy intervention. Brown (2012) spoke about vulnerability as encompassing uncertainty, risk, and emotional exposure, and described how people can use vulnerability to positively impact lives. The preservice teachers exposed their vulnerabilities in coming into this project with uncertainties about their own abilities to support the students. They were grateful to have been given the space to take some risks, learn, and gain confidence through the process.

CoPs to support emerging professionals. The literacy sessions and the CoP supported the preservice teachers in implementing the literacy intervention. They were quickly immersed into the project and implemented the literacy intervention in their small groups with a diverse group of young ELLs. As the intervention progressed, the preservice teachers also appreciated that they were a cohort of 11 at the research site and could depend on one another for support. In the focus groups, they elaborated upon the significance of the peer support through the cohort opportunity. Ariana said, "We have also all collaborated with being in the hall, and we talk about what is working and what is not working." This sentiment was reinforced by Seong, who said, "It's so nice to have people you can talk to and a support system! [And] eat lunch with." Finally, Elliott added,

Even when we met with [the practicum advisor], our first meeting for practicum, and we were going around ... there were one or two people that are only at the school, and it adds another element of how crazy and intimidating your practicum can be.

These three quotes capture the preservice teachers' appreciation of the cohort of 11 at the same school and the importance of the relationships they formed with one another and other school staff before starting their practicums.

Finding 3: Implementation of the intervention provided the preservice teachers with opportunities to connect practice and theory and to inform their future teaching experiences

Using DBR principles speaks to the importance of connecting theory and practice to address complex research problems. The preservice teachers identified a desire to have more exposure to practical learning experiences in working with ELLs and differentiating for diversity. In many ways, this project allowed the preservice teachers to connect the practice of doing to the theoretical underpinnings of supporting linguistic and cultural diversity for young ELLs. In this regard, the preservice teachers were able to make practical connections to the instructional dimensions of the Literacy Engagement Framework and provide the young ELLs with opportunities to engage with their learning through multimodal and multilingual literacy tasks. In the next section, I describe how the 
intervention deepened their pedagogical knowledge to support ELLs and allowed them to reflect on how linguistic and cultural diversity would impact their future practice.

Deepening of preservice teachers' pedagogical knowledge to support English Language Learners. The preservice teachers deepened their understanding of the seminal constructs of BICS and CALP (the difference between conversational and academic language). The distinction between conversational, social language and academic language skills is essential in understanding the complexity of literacy and language development for young ELLs (Cummins, 1989). Cummins (1981a) stated that while it may take up to 2 years to achieve social, conversational skills (Basic Interpersonal Communication Skills [BICS]), it will take 5 or more years for ELLs to achieve academic language proficiency (Cognitive Academic Language Proficiency [CALP]). While younger ELLs sound good and acquire BICS type language quickly (Roessingh 2018), CALP language, where there are cognitively demanding and context reduced situations, presents difficulties for them as curricular and linguistic demands escalate. There are fewer contextual clues to support students' understanding, and the language is more formal and abstract. They saw how the ELLs' language skills seemed strong at the onset of the project, but with more exposure, they realized how students were challenged with their academic language and in particular struggled with the project's writing opportunities. This finding is reflected in the following three quotes from the focus group data. Blake said, "I thought that the buddies would be at a lower level and was surprised at how much they knew, but at a closer look you realize how their comprehension is not really there." Jennifer added, "They would always ask me how to spell a word. I would ask them to try, but they didn't want to because they didn't want to be wrong. They didn't understand the phonics, really. They struggled a lot." And finally, Ariana said,

I think I learned a lot just in ... how language is learned through a kid's eyes. Spoken is so strong, but then written you're like, "You don't have the phonics." . . . They really struggled with [blending sounds]. Didn't get the "Th" sound. Conceptually they got things, but when it came to writing, it was a total disaster. Interesting.

The three quotes capture how the preservice teachers made sense of theoretical concepts such as BICS and CALP through their practical work with the ELLs and their reflections on their lessons. This pedagogical knowledge was important in assessing the ELLs' English language development and redesigning the lessons to differentiate the instruction.

Looking forward: Impact of cultural and linguistic diversity on future practice. The preservice teachers also recognized what impact cultural and linguistic diversity might have in their own practicum experiences and future classrooms. As Yana described,

How the ELLs are being assimilated into classes - they really need support. Even in the ELL class, they were coming up to me asking me for help in Arabic. It opened up my eyes to the ELL component, and when I am a future teacher, how many students are learning English, and how it would affect your overall classroom, and how you would have to take that and tweak that. It was really eye-opening for me. Helen described her experience as follows: 
I think it was such a neat experience being at such a diverse school and seeing how they treat the diversity and acknowledging it with the big map at the front of the school and really being proud of how many languages are spoken in the school. It was nice to see that because really, in the courses here at university, you don't really understand how diverse schools can be. Last semester at the practicums, the schools I was at, they were not very diverse.

The preservice teachers appreciated the opportunity to be in a diverse school for the service-learning project and recognized the value of first language and culture in their practice. They also reflected on the impact of the importance of affirming identity in the instructional design. Christina's lesson reflection captured this outcome as she described the impact Scribjab (Toohey \& Dagenais, 2010) had on affirming the students' identity and influencing her understanding. Scribjab is a multilingual digital storytelling application that was used in the literacy intervention to incorporate first language into the lessons.

I think Scribjab helped to establish their first language as something that is legitimately important. It's almost like they trust technology, and if the technology exists for this and if other people are doing this (as they see from the online Scribjab books from other authors), then being bilingual and having these cultural connections must be important. [S] and [Y] really enjoyed reading the books written by other authors in Arabic and Urdu. They were even critiquing the stories, wondering why the authors didn't write more, or asking questions indicating that they wanted to know more. I realized the importance for them of seeing the connection between the two languages being side by side simultaneously. (Christina)

Christina's quote is powerful as she critically reflected on how the ELLs responded to the use of Scribjab and how they related to the first language keyboards. Christina also recognized that the ELLs' engagement with the dual language aspect of the project was more evident during their use of Scribjab than it had been in previous lessons.

The preservice teachers started to make practical connections to theoretical underpinnings of the literacy engagement framework and a multiliteracies approach to instructional design by implementing the literacy sessions and reflecting on the strengths and areas for development of the lessons. Being part of the Name Jar Project provided the opportunity to have an informal learning experience in a diverse school setting where they could observe, try different strategies, and start to make their own connections between practice and theory. The pedagogical intent to embed first language and culture through the design provided insight into the use of strategies to include dual language instruction and affirm ELLs' identities. The preservice teachers also recognized the complexity of learning English and began to understand how that complexity could impact them as future teachers in their own classrooms. The literacy session reflections and the $\mathrm{CoP}$ allowed them to reflect on their own practice and how it has influenced them as emerging professionals. Being part of the service- learning project also supported their practicum experience as they employed strategies from the designed intervention.

\section{Discussion and Implications}

The preservice teachers consistently reflected on the service- learning project as a practical and valuable learning opportunity to deepen their understanding of how to 
differentiate instruction to support the ELLs' linguistic and cultural needs in a safe learning environment. The focus on experiential learning and the CoP structure (Wenger et al., 2002) was integral to supporting the preservice teachers in taking risks in adjusting their lessons, recognizing the importance of peer support in providing strategies and feedback, and beginning to critically reflect on their own values, perceptions, and assumptions about linguistic and cultural diversity. It would be worthwhile to continue these conversations at the postsecondary level and to provide opportunities for service -learning projects to expose pre-service teachers to creative informal learning opportunities to deepen their professional learning.

These findings also reinforced the need to continue to explore the role of differentiation for linguistic and cultural diversity within the coursework in education programs. The preservice teachers' perceptions that more support is needed in teacher education programs to differentiate instruction for ELLs is echoed in the literature (International Literacy Association, 2017; Kapoyannis, 2019; Ntelioglou et al., 2014). There was also the perception that supporting ELLs was only focused on in the ELL specialization courses within their program. The findings in this study revealed that the preservice teachers felt their teacher education program fell short of providing the pedagogical knowledge and experiential learning opportunities needed for them to feel prepared in effectively supporting the needs of ELLs. Continued exploration is needed in how preservice teacher education programs can provide opportunities for all preservice teachers to feel confident and knowledgeable in supporting the linguistic and cultural needs of ELLs.

The preservice teachers identified that being part of a cohort of 11 at one school was positive and valuable. Starting with the service -learning component, and then continuing to complete their field requirements, provided the preservice teachers opportunities to establish relationships with their students, their peers, and the larger school community. They had exposure to diverse learner profiles of students in different grades and learning environments, which fostered the opportunity to deepen their pedagogical knowledge and reflect on their practice as emerging professionals (Goldenberg, 2013; Roessingh, 2014). Although these types of cohort configurations may be difficult to arrange in a singular school setting, the positive implications are worthy of continued exploration.

Of critical importance was the preservice teachers' powerful observations made about the role of first language and culture in affirming the students' identity within the literacy intervention. As was amplified in the literature review, this is an area where educators need to be more intentional in their literacy practices (Cummins \& Early, 2011; Naqvi et al., 2012; Roessingh, 2011). The findings captured the positive influence on the young ELLs as they were encouraged to learn more about their languages and cultures and to share this learning with their peers through the use of the artifacts, creation of their identity texts and dual language opportunities. Preservice teachers need to continue to reflect on how to affirm their students' identity in their instructional design. Cummins reinforced the power of identity texts (Cummins \& Early, 2011; Cummins et al., 2015; Stille \&Prasad, 2015) where "students can showcase their intellectual, literary, artistic and multilingual talents in ways that challenge the devaluation of their cultures and identities in the school and wider society" (Cummins \& Early, 2011, p. 145). 
It is my hope that the Name Jar Project may provide stakeholders who are invested in preservice and inservice education with a positive exemplar to reflect on as educators respond to the diversity within multilingual and multicultural classrooms. The best DBR has a visionary quality, driven by potentiality of what can be (Bereiter, 2002). This is an exciting idea as educators look to inspire the next generation of diverse learners in Canada.

\section{References}

Alberta Teachers' Association. (2014). PD survey 2014: A retrospective in brief. https://www.teachers.ab.ca/SiteCollectionDocuments/ATA/Publications/Professio nal-Development/PD-183\%20PD\%20Survey\%202014 2015-07 Web.pdf

Alberta Education. (2010). Literacy first: A plan for action 2010. https://open.alberta.ca/publications/9780778585916

Amiel, T., \& Reeves, T. C. (2008). Design-based research and educational technology: Rethinking technology and the research agenda. Educational Technology and Society, 11(4), 29-40. https://www.jstor.org/stable/jeductechsoci.11.4.29

Anderson, T., \& Shattuck, J. (2012). Design-based research: A decade of progress in education research? Educational Researcher, 41, 16-25. https://doi.org/10.3102/0013189X11428813

August, D., \& Hakuta, K. (Eds). (1998). Educating language minority children. National Research Council, Institute of Medicine, National Academy Press.

Bereiter, C. (2002). Design research for sustained innovation. Cognitive Studies: Bulletin of the Japanese Cognitive Science Society, 9(3), 321-327. https://www.jstage.jst.go.jp/article/jcss/9/3/9 3 321/_pdf

Brown, A. (1992). Design experiments: Theoretical and methodological challenges in creating complex interventions in classroom settings. The Journal of the Learning Sciences, 2(2), 141-178. https://doi.org/10.1207/s15327809j1s0202_ 2

Choi, Y. (2001). The name jar. Dragonfly Books.

Collier, V. P. (1995a). Acquiring a second language for school: Directions in language and education (Vol. 1). National Clearinghouse for Bilingual Education.

Collier, V. P. (1995b). Promoting academic success for ESL students: Understanding second language acquisition for school. New Jersey Teachers of English to Speakers of Other Languages-Bilingual Education.

Cope, B., \& Kalantzis, M. (2009). "Multiliteracies": New literacies, new learning. Pedagogies: An International Journal, 4, 164-195. https://doi.org/10.1080/15544800903076044

Cummins, J. (1981). Age on arrival and immigrant second language learning in Canada: A reassessment. Applied Linguistics, 2, 132-149. https://doi.org/10.1093/applin/11.2.132

Cummins, J. (1989). Empowering minority students. California Association for Bilingual Education.

Cummins, J. (2011a). Literacy engagement: Fueling academic growth for English learners. The Reading Teacher, 65(2), 142-146. http://dx.doi.org/10.1002/TRTR.01022 
Cummins, J. (2011b). Putting the evidence back into evidence-based policies for underachieving students. Council of Europe.

Cummins, J., \& Early, M. (Eds.). (2011). Identity texts: The collaborative creation of power in multilingual schools. Trentham Books.

Cummins, J., Hu. S., Markus, P., \& Montero, M. K. (2015). Identity texts and academic achievement: Connecting the dots in multilingual school contexts. TESOL Quarterly, 49(3), 555-581. https://doi.org/10.1002/tesq.241

Dominice, P. (2000). Using educational biographies with adults. Jossey- Bass.

Escamilla, C. (2009). English language learners: Developing literacy in second-language learners: Report on the national literacy panel on language-minority children and youth. Journal of Literacy Research, 41(4), 432-452. https://doi.org/10.1080/10862960903340165

Freeman, Y., \& Freeman, D. (2004). Connecting students to culturally relevant texts, National Council of Teachers of English. https://education.alberta.ca/media/ 3402192/lit-and-num-progressions.pdf

Goldenberg, C. (2013, Summer). Unlocking the research on English learners: What we know - and don't know - about effective instruction. American Educator, 4-38. https://dataworks-ed.com/wp-content/uploads/2016/05/Goldenberg.pdf

Howard Research \& Management Consulting. (2006). A review of K-12 ESL education in Alberta: Study synopsis. https://open.alberta.ca/publications/077855158x

Howard Research \& Management Consulting. (2009). Kindergarten to grade 12 English as a second language literature review update. http://education.alberta.ca/media/1182477/esl_lit_review.pdf

International Literacy Association. (2017). What's hot in literacy. https://www.literacyworldwide.org/docs/default-source/resourcedocuments/whats-hot-2017-report.pdf?sfvrsn=4

Kapoyannis, T. (2019). Literacy Engagement in Multilingual and Multicultural Learning Spaces. TESL Canada Journal, 36(2), 1-25. https://doi.org/10.18806/tesl.v36i2.1298

Kramsch, C. (2004). The multilingual experience: Insights from language memoirs. TRANSIT, 1(1). http://repositories.cdlib.org

Linan-Thompson, S., \& Vaughn, S. (2007). Research-based methods of reading instruction for English language learners: Grades K-4. Association for Supervision and Curriculum Development.

Lindsay, J. (2010). Children's access to print material and education-related outcomes: Findings from a meta-analytic review. Learning Point Associates.

Lincoln, Y. S., \& Guba, E. G. (1985). Naturalistic inquiry. Sage.

McKenney, S., \& Reeves, T. C. (2012). Conducting educational design research. Taylor and Francis.

Morgan, D. L. (2008). Focus groups. In L. M. Given (Ed.), The Sage encyclopedia of qualitative research methods (pp. 353-355). Sage. 
Naqvi, R., McKeough, A., Thorne, K., \& Pfitscher, C. (2012). Dual language books as an emergent literacy resource: Culturally and linguistically responsive teaching and learning. Journal of Early Childhood Literacy, 13(4), 501-528. https://doi.org/10.1177/1468798412442886

New London Group. (1996). A pedagogy of multiliteracies: Designing social futures. Harvard Educational Review, 66(1), 6-92.

Onwuegbuzie, J. A., Dickinson, W. B., Leech, N. L., \& Zoran, A. G. (2009). A qualitative framework for collecting and analyzing data in focus group research. International Journal of Qualitative Methods, 8(3), 1-21. https://doi.org/10.1177/160940690900800301

Parry, K. W. (2004). Constant comparison. In M. S. Lewis-Beck., A. Bryman, \& T. Futing Liao (Eds.), The Sage encyclopedia of science research methods (pp. 181182). Sage.

Roessingh, H. (2010). Learning by design. http://esllearningbydesign.com/

Roessingh, H. (2011). Family treasures: A dual-language book project for negotiating, language, literacy, culture and identity. The Canadian Modern Language Review, 67(41), 123-148. https://doi.org/10.3138/cmlr.67.1.123

Roessingh, H. (2018). Unmasking the early language and literacy needs of ELLs: What K-3 practitioners need to know and do. BC Teal Journal, 3(1), 22-36.

Roessingh, H., \& Kover, P. (2003). ESL learners' acquisition of cognitive academic language proficiency: What can we learn from achievement measures? TESL Canada, 21(1), 1-21. https://doi.org/10.18806/tesl.v21i1.271

Samson, J. F., \& Collins, A. (2012). Preparing all teachers to meet the needs of English language learners: Applying research to policy.

https://cdn.americanprogress.org/wpcontent/uploads/issues/2012/04/pdf/ell report.pdf

Statistics Canada. (2017). A look at immigration, ethnocultural diversity and language in Canada up to 2036, 2011 to 2036. http://www.statcan.gc.ca/dailyquotidien/170125/dq170125b-eng.pdf

Stille, S., \& Prasad, G. (2015). "Imaginings": Reflections on plurilingual students' creative multimodal works. TESOL Quarterly, 49(3), 608-621. https://doi.org/10.1002/tesq.240

Strauss A., \& Corbin, J. (1998). Basics of qualitative research: Techniques and procedures for developing grounded theory. Sage.

Toohey, K., \& Dagenais, D. (2010). Scribjab. http://www.scribjab.com/

Wenger, E., McDermott, R., \& Snyder, W. M. (2002). Cultivating communities of practice: A guide to managing knowledge. Harvard Business School Press.

Author Biograpghy

Theodora Kapoyannis is the Director of Field Experience (On-Campus Program) in the Werklund School of Education at the University of Calgary. Before completing her PhD in Languages and Diversity in 2018, she served in many instructional leadership roles within K- 12 schools and has been a consultant for various non- profit organizations. Her research interests include language learning, literacy, pre-service education, adult learning, diversity, and design- based research. 


\section{Appendix A: Focus Group Questions}

\section{Initial Focus Group}

1. How would you describe literacy engagement?

2. What have your experiences been so far working with ELLs as preservice teachers?

3. How would you describe your readiness in supporting literacy practices for ELLs?

4. What do you hope to gain from participating in this research project?

\section{Second Focus Group}

1. What has your experience been participating in this ELL literacy intervention?

2. What do you feel is working well with the intervention and why?

3. What challenges have you encountered with the literacy intervention and why do you believe these are challenges?

4. What would you recommend to further improve the intervention? 


\section{Date:}

Project: The Name Jar: Identity

Age/Grade: 2-3

\section{Lesson Overview}

\section{Objectives}

\begin{tabular}{|c|c|c|}
\hline $\begin{array}{c}\text { Language Learning } \\
\text { Objectives }\end{array}$ & Concept/curricular Objectives & Strategy Objectives \\
\hline & & \\
\hline
\end{tabular}

\section{Teaching Phase}

- Warm Up: Review/recycling

- New language, concepts, strategies

- Planning for next lesson

Learning tasks: Transforming, Practicing, Reinforcing, Extending

$\bullet$

\begin{tabular}{|l|l|}
\hline NEW & Grammar, Function, Focus \\
RECYCLED & \\
\hline
\end{tabular}

Observations and Reflections

My observations and reflections:

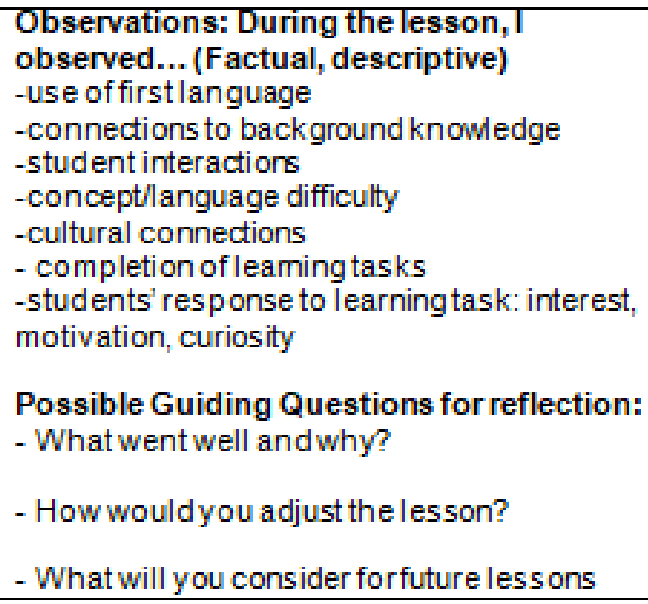

